\title{
Door Security System Using e-KTP RFID Reading and Passive Infrared Sensor
}

\author{
Mohammad Adrian Faisal ${ }^{1}$ and Erwin Sitompul ${ }^{1 *}$ \\ ${ }^{1}$ Study Program of Electrical Engineering, President University, Bekasi 17550, Indonesia \\ *Corresponding author: sitompul@president.ac.id
}

\begin{abstract}
A door, as a barrier to limit an access between two spaces, requires a security measure to ensure that only privileged people may pass. In this paper, a door security system using Radio Frequency Identification (RFID) and Passive Infrared (PIR) sensor is proposed. This security system utilizes an electric door lock and an e-KTP (Kartu Tanda Penduduk elektronik/ electronic Indonesian Identity Card) as the key. A sequence of numbers can be read from an e KTP by using an RFID reader. This sequence is unique, making an e-KTP suitable to be used as a key. Furthermore, the door security system is equipped with an alarm. A PIR is used to detect motion, and the alarm will sound if someone passes the door while the alarm is still in active state. The Arduino Mega microcontroller board is used to organize the whole system, consisting the aforementioned reader and sensor, along with two push-buttons, a buzzer, and a solenoid door lock. The system is realized into a prototype in the form of door miniature. A list of scenarios is played through to the system. Only authorized e-KTPs can be used to unlock the door and deactivate the alarm. The door security system successfully fulfils the objective to improve the security level of a door lock mechanism by utilizing an e-KTP as a unique RFID key and by featuring a PIR-integrated alarm.
\end{abstract}

Keywords: e-KTP (Kartu Tanda Penduduk elektronik / electronic Indonesian Identity Card), Passive Infrared Sensor (PIR), Radio Frequency Identification (RFID)

\section{INTRODUCTION}

According to one definition, a door is a swinging or sliding barrier by which an entry to a room, building, or vehicle is closed and opened [1]. As a barrier, a door can be meant as a privileged to a certain space.

A door lock mechanism consists of a latch or bold, which can slide across an opening between the door leaf and the door frame, thus denying access. A door lock can be fastened or released mechanically by using a mechanical key, as can be found at traditional door locks. Mechanical keys are vulnerable to be duplicated. Provided with only short physical access to those keys, a picture or a sketch can already give enough information for the key to be copied. Some keys may require extensive skill or equipment to duplicate, but it tends to be possible.

On the other hand, the latch of a door lock can also be moved by using an electronic key such as keycard, fingerprint, personal identification number, and RFID (Radio Frequency Identification). In this kind of door lock, an actuator is installed to move the latch. Electronic keys, in theory, are also prone to forgery. However, by the implementation of digital technology and techniques, duplication can be made extremely difficult [2].

RFID, as one possible choice of electronic key, is a contactless transfer of data with the use of radio frequency between a data-carrying device and its reader. The power required by the data-carrying device can also be transmitted from the reader by using contactless technology [3].
e-KTP (Kartu Tanda Penduduk Elektronik/ electronic Indonesian Identity Card) uses RFID to transfer the data saved in its memory to a reader. The data stored in this memory is encrypted and can only be read completely by a reader equipped with a secure access module [4]. However, common RFID readers still can read a tag identification, which is unique for each e-KTP.

Thus, in this given condition, having an e-KTP as a key means having a secure key that will require extraordinary effort to duplicate. The application of e-KTP as an electronic key also increases the usefulness of the card and simplicity for the owner, because most people always bring their e KTPs everywhere for eventual proof of identity.

A safety design of automatic door using e-KTP has been proposed in [5]. An additional feature for access record can be found in [6]. However, an alarm system is missing in both cases. Once the door lock is breached, any intruder will be able to enter without any further hindrance.

In this paper, a door security system using e-KTP as the key is proposed. This system is expected to offer improved security and convenience. This is because e-KTP is individually owned and is always taken everywhere by the owner. Furthermore, the door security system will be equipped with an infrared sensor to detect human presence. In case the door is breached, an alarm will be triggered. Thus, any unauthorized entry can be known.

\section{LiteratURE REVIEW}

A. RFID

An RFID system uses wireless radio communication to 
uniquely identify tagged objects. Fig. 1 shows three basic components of an RFID system: a tag, a reader (or reader/ writer), and a controller.

A tag is composed of a semiconductor chip, an antenna, and sometimes a battery. A reader also has an antenna, along with a radio frequency module and a control module. A controller is a host that runs the database and the control of the system [7].

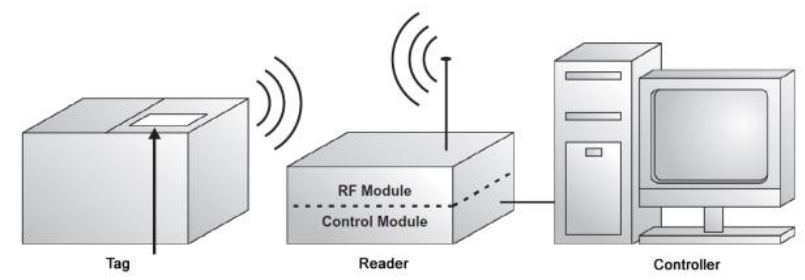

Figure 1. Basic Components of an RFID System

The RFID reader communicates with the RFID tag through electromagnetic radio waves. The antenna of the reader propagates the waves to the nearby tag. The energy from the waves is used by the tag's antenna to generate electric current. The current flows and turns on the chip of the tag to store, process, and send data of its memory. The required information is modulated with the received waves and directed back to the reader by using the tag's antenna.

e-KTP is designed to operate by using RFID technology. The chip inside the e-KTP, as illustrated in Fig. 2, contains personal information of the holder as written on the card, together with the signature, photo, and fingerprints. All this data is stored in an $8-\mathrm{kB}$ memory of the chip [8].

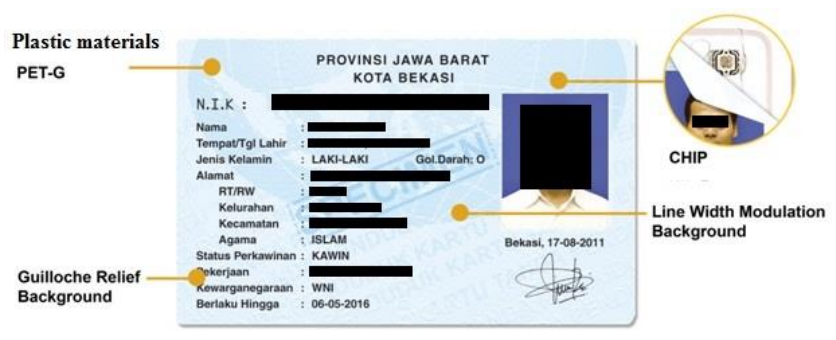

Figure 2. A Sample of e-KTP With A Chip Inside [8]

Indeed, the data is highly protected in which the communication between an e-KTP as a RFID tag and its RFID reader is secured by the use of random number generator and bidirectional authentication [4]. This means that only an RFID reader operated with a certain secure access module may access the data inside the chip. However, if read with a common RFID reader working at suited frequency, an e-KTP will still send back something called tag identification. This tag identification is unique for each e-KTP. Thus, an e-KPT can be utilized as an electronic key for electronic door lock.

Fig. 3 shows the MFRC522. It is an RFID reader/ writer that follows ISO/IEC 14443 standard. This module is able to transmit using various speeds and modulation protocols. The contactless RFID communication is performed at $13.46 \mathrm{MHz}$ [9]. The standard of MFRC522 meets the requirement of e-KTP reader [4]. Therefore, if an
e-KTP is present in the vicinity of an MFRC522, the module will give a response by reading the tag identification of the e-KTP.

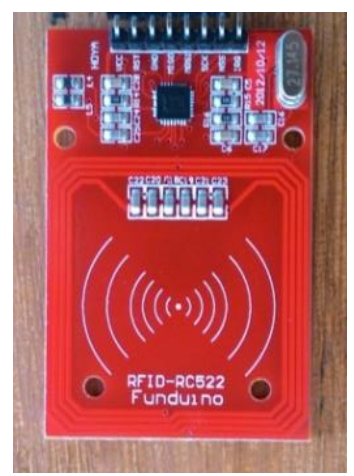

Figure 3. RFID Reader MFRC522

\section{B. $\quad P I R$}

Further sensor used in the proposed door security system is a passive infrared (PIR) sensor, as can be seen in Fig. 4. The sensing part of the PIR sensor is a pyroelectric material. Through the sensing of changes in the infrared levels emitted by the surrounding objects, this sensor can detect motion. In other words, this sensor is sensitive to a sudden change in the surrounding infrared pattern [10].

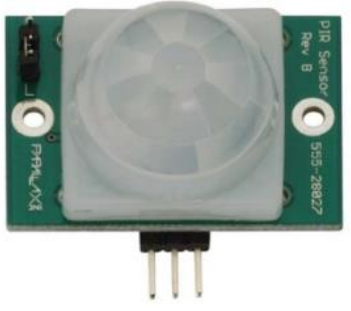

Figure 4. PIR Sensor [10]

As human body emits infrared radiation, the PIR sensor can be used to detect the presence of human. If a person walks across the operating range of the sensor, the ambient infrared signals will change rapidly and the sensor's output turns high to indicate the person's motion. In the proposed door security system, this logic signal will be interpreted as an intrusion and a certain security measure can be further performed.

After choosing the MFRC522 as the RFID reader for the e-KTP as the RFID tag, the next important part to construct the proposed door security system is a locking mechanism that can be controlled electronically. A solenoid door lock, as shown in Fig. 5, is the solution chosen by the author.

\section{Solenoid Door Lock}

Solenoid is a term for a coil of wire used to convert electrical energy to mechanical energy. The solenoid creates a magnetic field from direct electric current and uses the magnetic field to create force and motion. 


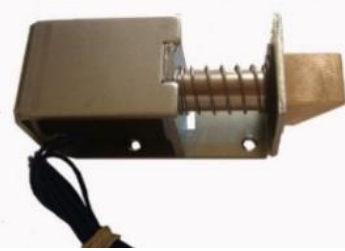

Figure 5. Solenoid Door Lock

A solenoid door lock is a remote door locking mechanism which utilizes electromagnetic force to move its latch. As mentioned earlier, the force is created by the current flowing through a low-voltage solenoid. The current flow is governed by a controller. The latch can be in normally lock or normally unlock position. If current is fed to the solenoid, the latch will move, and if the current is stopped, the latch will return to its original position.

A solenoid door lock requires relatively high electric current. In order to be fully operable, the switch of solenoid door lock needs a supporting circuit consisted of components such as a power transistor, a diode, and resistors.

\section{Design Specification}

The door security system also consists of an LCD (Liquid Crystal Display) as user interface. It will indicate the state of the process or show messages to the user. An electric buzzer is used as acoustical alarm in case someone breaches the door and comes across it. Furthermore, 2 push-buttons are included to the system. The first pushbutton will be used to open the door from the rear side, while the second push-button is to deactivate and reactivate the alarm.

To avoid problem caused by power line failure, where an electronic key will remain locked or unlocked, the door security system is also fitted with an accumulator. The accumulator serves to bridge the power supply until the electricity is restored. A relay is installed as an automatic switch between the power adaptor, which is supplied by the power line, and the accumulator.

Arduino Mega 2560 is chosen as the microcontroller of the door security system. Arduino Mega is a microcontroller board based on the Atmel AVR ATmega 2560 microcontroller [12]. Arduino Mega has 54 digital $\mathrm{I} / \mathrm{O}$ pins and 16 analog pins. This considerable number of pins is necessary due to the corresponding large number of the system's components required to be connected to the microcontroller.

The block diagram of the door security system is shown in Fig. 6. The blue lines indicate the flow of data or information. The red lines denote the flow of electric power.

\section{DESIGN IMPLEMENTATION}

The security door lock system is now implemented, with the assembly of working hardware circuits and the programming of required software. A miniature door consisting of a door leaf and a door frame are built as the place to set up the components and the cabling.

The RFID reader MFRC522 is connected to the Arduino Mega with pin configuration as seen in Fig. 7. As many as 5 terminals out of the MFRC522 are connected to the digital pins of Arduino, excluding the terminals for power and ground. MFRC522 is connected through the SPI (serial peripheral interface) to the Arduino Mega 2560.

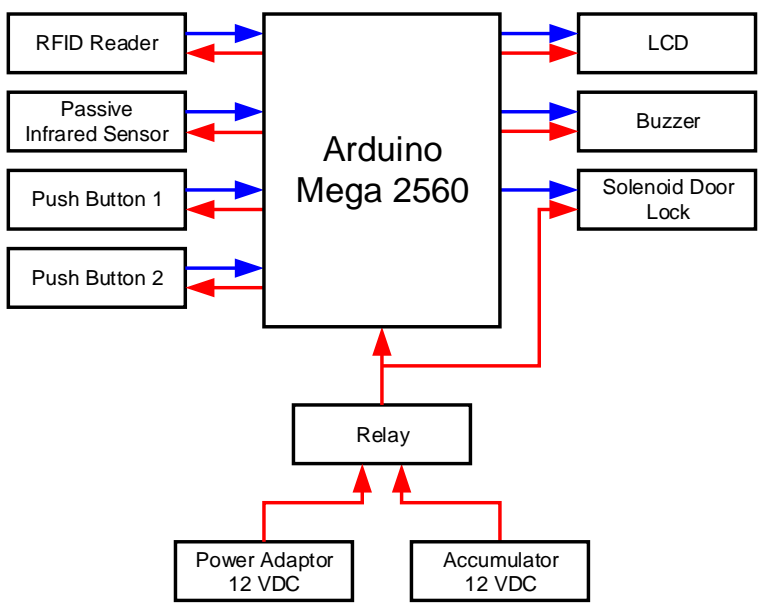

Figure 6. Block Diagram of the Proposed System

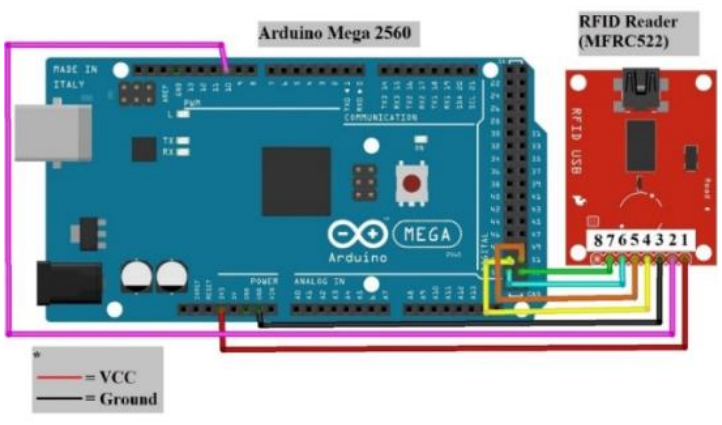

Figure 7. Pin Connections Between RFID Reader MFRC522 and Arduino Mega 2560

Subsequently, the PIR sensor, the buzzer, and the two push-buttons are connected to the Arduino Mega with arrangement as can be seen in Fig. 8.

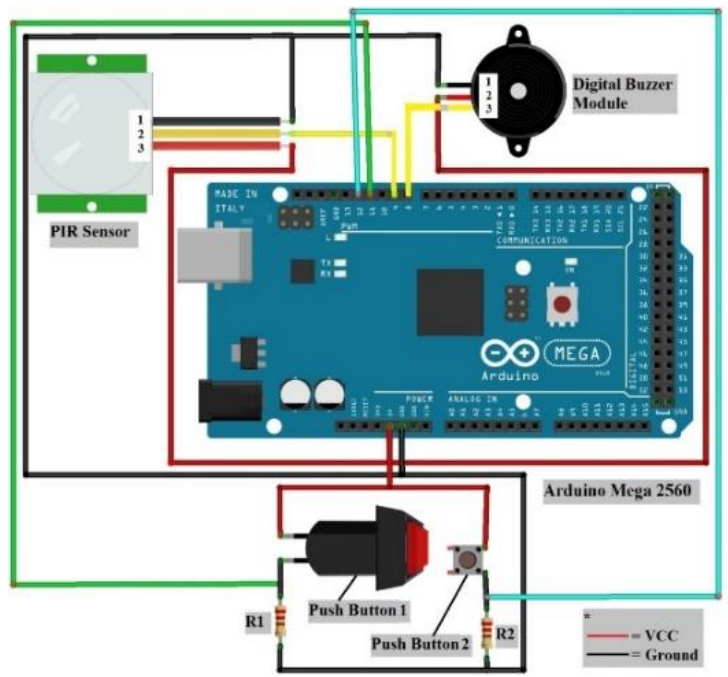

Figure 8. Connections Among PIR Sensor, Buzzer, Two Push Buttons, and Arduino Mega 2560 
The voltage of the power supply for the system is adjusted to the need of the solenoid door lock, 12 VDC. The power adaptor's output voltage is 18 VDC. The accumulator, intended to be a power back up, delivers an output voltage of approximately 13 VDC. Both power sources are connected to a $12 \mathrm{VDC}$ voltage regulator via a relay. This arrangement can be seen Fig. 9.

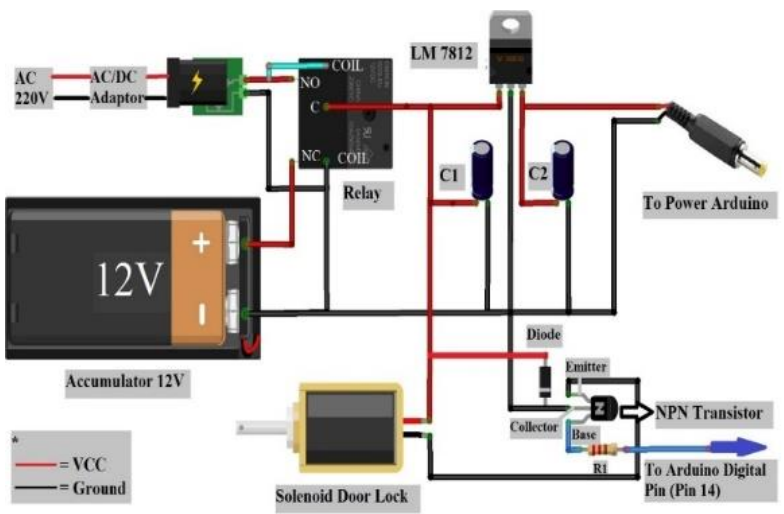

Figure 9. Circuit of Power Supply, Accumulator, Voltage, Regulator, and Solenoid Door Lock

The software programming of Arduino Mega 2560 is conducted by using Arduino IDE. The Arduino programs are written in $\mathrm{C}++$, with an addition of special methods and functions. The written program is used to process all the values acquired from the input pins and send the control values to the output pins.

The door security system is built into a prototype by installing all the hardware to a miniature door. Both the door leaf and the door frame are made of wood. The front view of the prototype can be seen in Fig. 10. The LCD and the RFID reader are mounted on the front side of the door leaf.

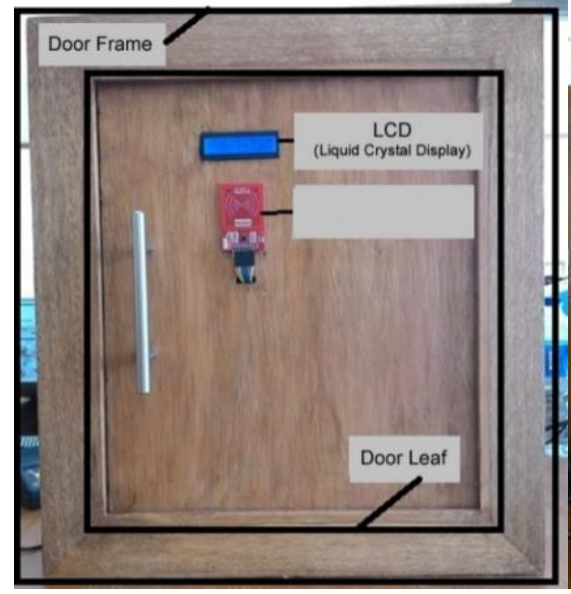

(a)

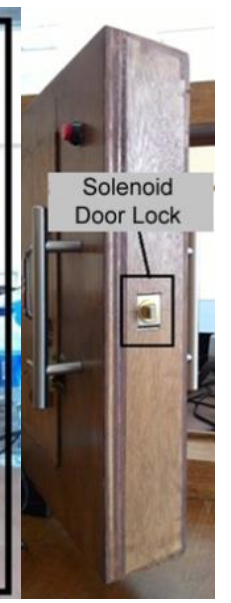

(b)
Figure 10. The Door Leaf; (a) Front View, (b) Side View

At the rear side of the door leaf, the Push-Button 1 is placed at upper right position. The space inside the door leaf is used as a compartment to place the components and the cabling, as can be seen in Fig. 11. The Arduino Mega, the Push-Button 2, and the buzzer can be found in this compartment. The accumulator, the relay, and the supporting circuits (for the LCD, the voltage regulator, and the solenoid door lock) are also fitted inside this space.

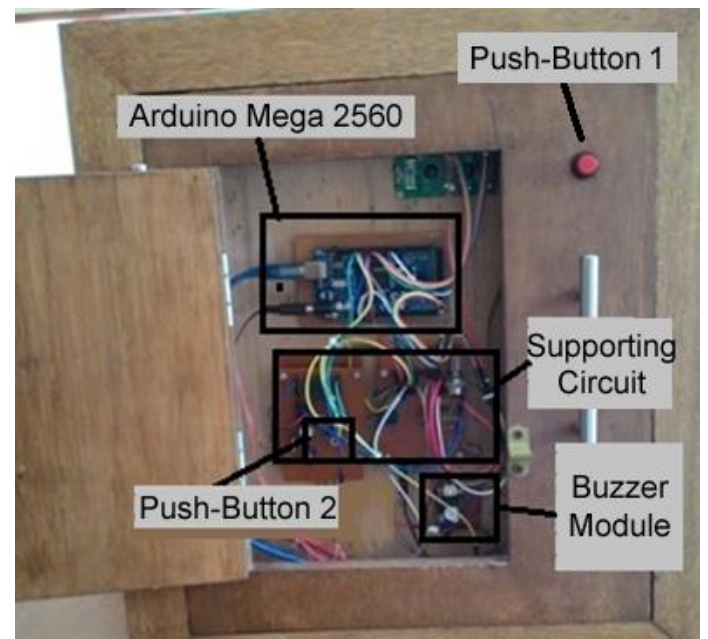

Figure 11. Compartment Inside the Door Leaf

The top view of the door frame, as shown in Fig. 12, shows the position of the PIR sensor. A hole is drilled through the top side of the door frame. The lens of the PIR sensor is set heading downward. The sensor is ready to detect the motion of any object with intense infrared radiation.

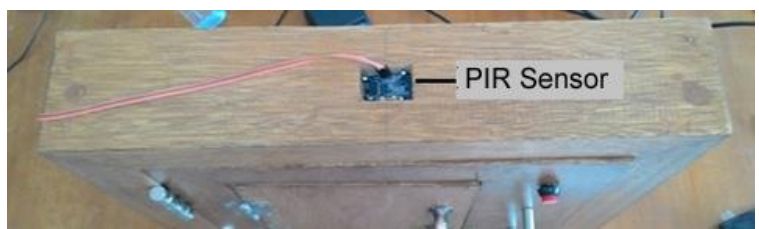

Figure 12. Top View of the Door Frame

The flowcharts of the door security system can be seen in Fig. 13 for the door lock part and in Figure 14 for the alarm part. As depicted in Figure 13, the solenoid door lock can be open from the rear side, by pressing the PushButton 1. When this button is pressed, the door can be open from the rear side. In case this button is not pressed, the RFID reader is ready to read any nearby e-KTP.

The tag identification of 2 e-KTPs were read beforehand and written in the system program. Only these identity cards, e-KTP 1 and e-KTP 2 are authorized and can open the door. If the RFID reader detects an authorized e-KTP nearby, for the duration of 10 seconds the solenoid door lock will be unlocked and the alarm will be deactivated. During this time, the person holding the authorized e-KTP can come into the room and then close the door firmly. When the given time is over, the solenoid door lock returns to lock position and the PIR sensor is reactivated.

In the case that the door needs to be open for a longer period of time than 10 seconds, i.e., for repeated in and out movements or for letting a number of people passing at the same time, the alarm can be deactivated by pressing the Push-Button 2. The step-by-step progression of the procedure can be seen in Fig. 14. If a person passes an open door after the 10 -second period is over, or if the person breaks the lock and passes the door, then the PIR 
sensor will detect the human presence and the alarm will be triggered. The buzzer will sound for 18 seconds.

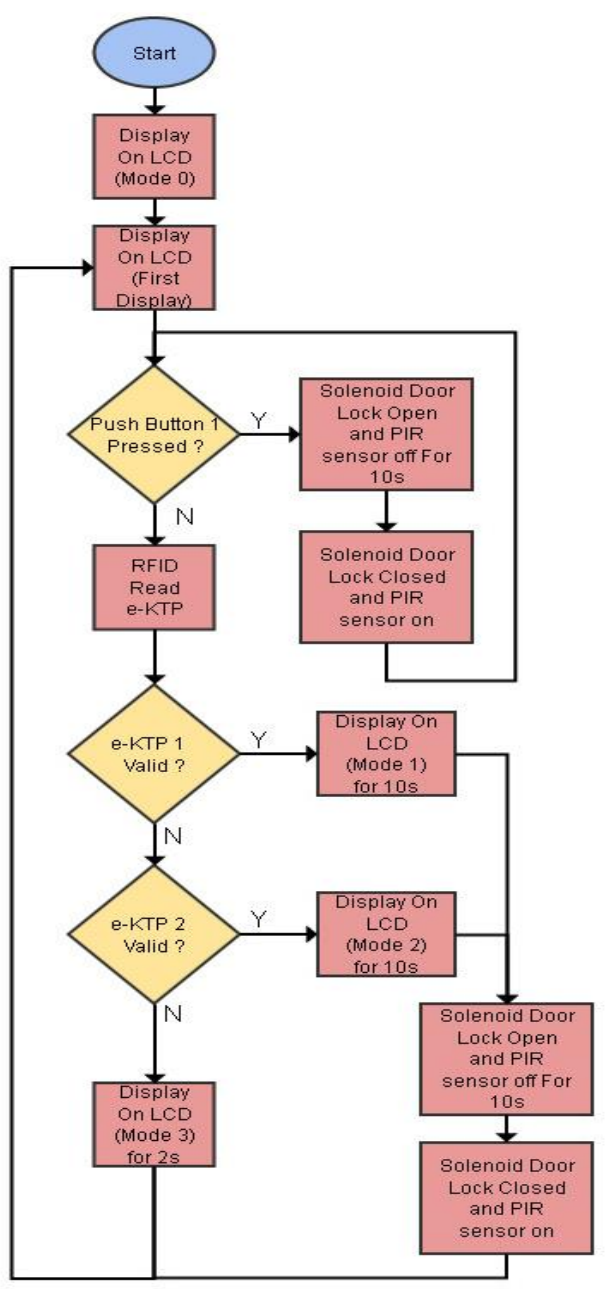

Figure 13. Flow Chart of the Door Security System Door Lock Part

\section{Testing Result AND ANALYSIS}

\section{A. Testing of the Solenoid Door Lock}

The solenoid door lock is in normally lock position when there is no current flown to it, as can be seen in Fig. 15(a). If the Arduino sends a high signal to the power transistor circuit, current will flow to the solenoid and open the lock, as shown in Fig. 15(b).

\section{B. System Initiation}

If the door security system is powered up, the LCD will promptly display the message "Calibrating PIR for $10 \mathrm{~s}$ ". When this time has passed, the LCD will show a new message "Welcome Waiting e-KTP", as shown in Fig. 16.

\section{Identifying Authorized e-KTP}

Two e-KTPs are registered in the Arduino program. If one of these authorized e-KTPs is placed near the RFID reader, the reader scans the e-KTP. Then, the LCD will display the message "e-KTP Valid," as shown in Fig. 17. Here, the solenoid door lock will be unlocked. The person can pass the door, and shall directly close the door tightly.

\section{Identifying Invalid e-KTP}

If any other e-KTPs are put close to the RFID reader, the message "e-KTP Not Valid" will be shown, as can be seen in Fig. 18. Here, the solenoid door lock will be unlocked and the person can pass the door, and shall directly close the door tightly.

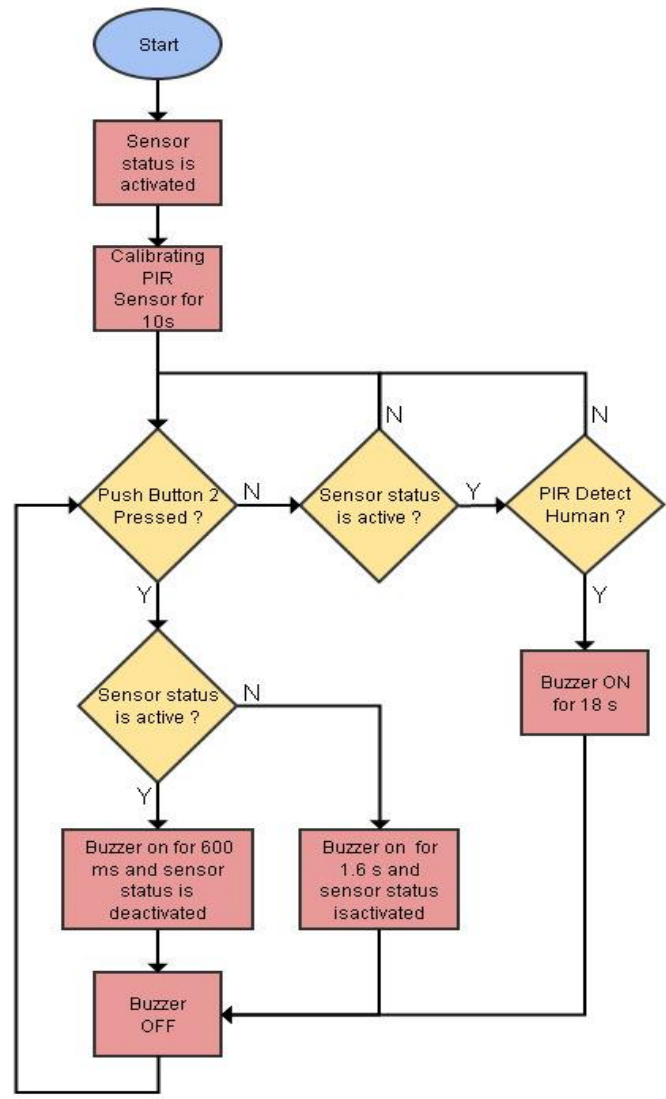

Figure 14. Flow Chart of the Door Security System: Alarm Part

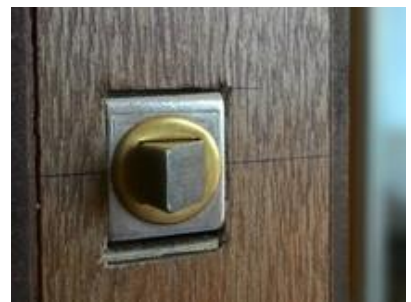

(a)

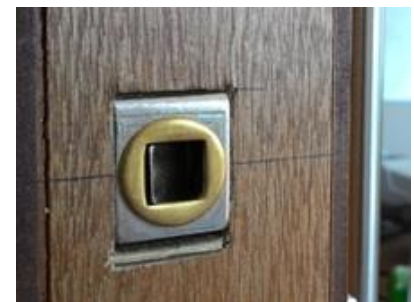

(b)
Figure 15. Solenoid Door Lock; (a) Normally Lock Position, (b) Unlock Position

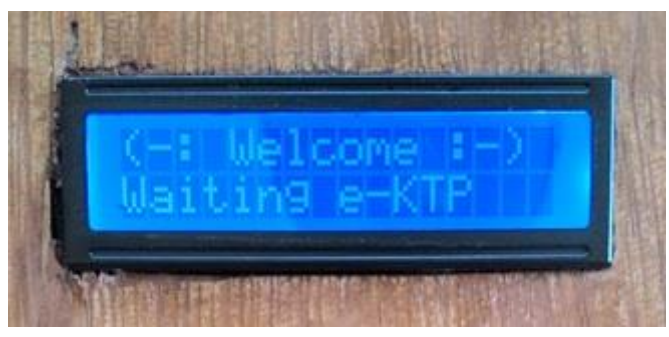

Figure 16. System After Initiation (First Display) 


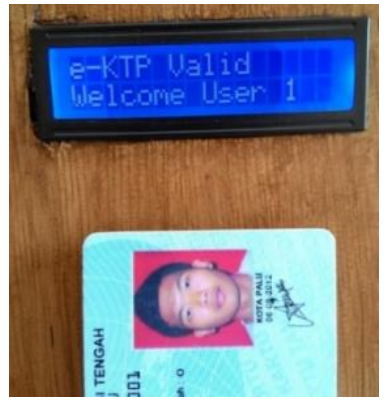

(a)

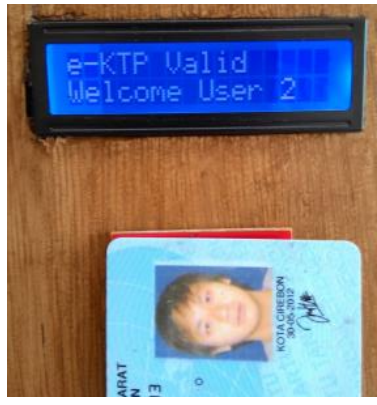

(b)
Figure 17. Display When Authorized e-KTPs are read; (a) User 1 (Mode 1), (b) User 2 (Mode 2)

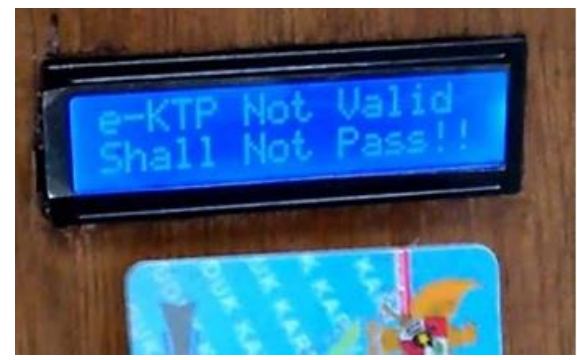

Figure 18. Display When Unauthorized e-KTP is read (Mode 3)

\section{E. Analysis}

The door security system is proved to work in approving only authorized e-KTPs to open the door. Besides, the functionality of the Push-Button 1, the PushButton 2, the PIR sensor and the related buzzer is also tested by using a set of scenarios, all with successful results. The power supply directly switches from the power adaptor to the accumulator in case the power breakdown occurs.

\section{CONCLUSION}

A door security system using e-KTP with RFID reading as electronic key and PIR sensor as motion sensor is proposed. The use of e-KTP as the electronic key offers the convenience and improved security. These are because e KTP is an official identity card that everyone already carries and it has a unique tag identification that is very difficult to copy. The use of PIR sensor as motion sensor gives additional protection, with a buzzer sounding if someone passes the door while the alarm is still activated. The operationality of the door security system is secured by having an accumulator as power back up. Herewith, the door can still be opened in case of power break down.

The prototype of the system is built in the form of door miniature. All possible events are tested as input to the RFID reader, PIR sensor, the push-button to unlock the door from the rear side, and the push-button to deactivate and reactivate the alarm. The outputs performed by the solenoid door lock and the buzzer are as expected by the design. The results shown by the prototype is completely perfect. Based on this fact, the project is considered as successful.

Further improvements can be done to the recording of additional e-KTP's tag identification and the charging of the accumulator. Instead of storing this data in the Arduino's system program manually, a procedure can be developed to automatically read the tag identification and to directly write it in the memory of the microcontroller. An automatic charger for the accumulator will maximize the charging process while the electricity is available. This ensures that the accumulator will be in best capacity anytime the power failure occurs.

\section{REFERENCE}

[1] Merriam-Webster Dictionary, Merriam-Webster Mass Market, Revised Edition, 2004.

[2] Independent Security Evaluators, Mechanical vs. Electronic Locks: Security Implications of the two paradigm, October 12, 2014. [Online]. Available: https://www.securityevaluators.com. [Accessed September 12, 2016].

[3] K. Finkenzeller, Fundamentals and Applications in Contactless Smart Cards, Radio Frequency Identification and Near-Field Communication, John Wiley \& Sons, Third Edition, 2010

[4] Ditjen Peraturan Perundang-undangan, Peraturan Menteri Dalam Negeri Republik Indonesia Nomor 6 Tahun 2011Tentang Perubahan Atas Peraturan Menteri Dalam Negeri Nomor 38 Tahun 2009 Tentang Standar Dan Spesifikasi Perangkat Keras, Perangkat Lunak Dan Blangko Kartu Tanda Penduduk Berbasis Nomor Induk Kependudukan Secara Nasional, Kementerian Hukum dan HAM, January 21, 2011. [Online]. Available: http://ditjenpp.kemenkumham. go.id. [Accessed February 22, 2016].

[5] E. Saputro and H. Wibawanto, Rancang Bangun Pengaman Pintu Otomatis Menggunakan e-KTP Berbasis Mikrokontroler ATmega 328, Jurnal Teknik Elektro, Vol. 8, No. 1, 2016.

[6] S. Riyadi and R. Heriyanto, Aplikasi Smart Card e-KTP Berbasis RFID Untuk Sistem Keamanan Ruangan, Elektra, Vol. 2, No. 2, Juli 2017.

[7] V. D. Hunt, A. Puglia, and M. Puglia, RFID - A Guide to Radio Frequency Identification, Wiley \& Sons, 2007.

[8] Badan Pengkajian dan Penerapan Teknologi, Press Release EKtp Pusat Teknologi Informasi Dan Komunikasi - BPPT, [Online]. Available: https://www.bppt.go.id. [Accessed September 1, 2016].

[9] NXP Semiconductors N. V., MFRC522 Data Sheet, April 27, 2016. [Online]. Available: https://www.nxp.com. [Accessed July 5, 2016].

[10] Parallax Inc., PIR Sensor Product Guide, March 27, 2014. [Online]. Available: https://www.parallax.com. [Accessed June 25, 2016].

[11] Adafruit, Lock-style Solenoid - 12 VDC. [Online]. Available: https://www.adafruit.com. [Accessed June 27, 2016].

[12] Arduino, Arduino Mega 2560 Data Sheet. [Online]. Availabe: https://store.arduino.cc. [Accessed October 1, 2015]. 